\title{
Manifestaciones alérgicas en Oftalmología. 2. Queratitis ulcerativa y glaucoma agudo recidivante por sensibilización parasitaria a Ascaris lumbricoides y Entamoeba histolytica
}

\author{
por \\ Otto Jiménez-Quirós* \\ Alexis Agüero S.** y ${ }^{*} \quad$ Rodrigo Saborío E.**
}

(Recibido para su publicación el 3 de mayo de 1961)

En un estudio reciente JiMÉNEZ-QUiRós et al. (21) señalaron la posibilidad de sensibilización de los diversos tejidos oculares en sujetos alérgicos, a sustancias que demuestren in vitro o in vivo capacidad alergénica. Sin embargo, los nexos entre endoparásitos y manifestaciones alérgicas en oftalmología no han sido bien estudiados aún, aunque se conozca relativamente bien la actividad alergénica de algunos helmintos y protozoarios.

De acuerdo con los trabajos de HANSEN y BERger (13), JADASSOHN (16) y Fuelleborn y Kikut (12) no puede dudarse que el antígeno de Ascaris da lugar a sensibilización y que los anticuerpos específicos perduran toda la vida. Dicha sensibilización, como lo demostró ZoHN (34) puede tener lugar aun en el feto por vía transplacentaria.

Sobre la constitución química de los antígenos de Ascaris y su relación inmunológica se han realizado numerosos trabajos y entre los dignos de citarse están los de Campbell (2), Oliver-González (30) y Kagan et al. (22).

En referencia a manifestaciones alérgicas producidas por el parásito. VANNi (33), Kourí (24), Lippi y Tripodi (25), Capuani (3), Earl (11), Alimuddin (1), JimÉnez-Quirós (17), Jiménez-Quirós et al. (19), y otros, han señalado ya, entre la gama muy variada de manifestaciones, aquellas que comprometen en modo particular conjuntiva y piel circunvecina.

A partir del clásico trabajo de CRAIG (7) se han realizado numerosas investigaciones con el fin de demostrar la presencia de sustancias hemolíticas y citolíticas antigénicas derivadas de Entamoeba bistolytica. El mismo C.CRAIG (8)

* Sección de Salud y Departamento de Parasitología de la Universidad de Costa Rica.

* Servicio de Oftalmología del Hospital San Juan de Dios. 
demostró poco después, que la reacción que lleva su nombre es sólo positiva en el noventa por ciento de los casos con sintomatología intestinal o hepática, y que los anticuerpos manifiestan su labilidad al negativizarse aquella una vez curados los enfermos.

Recientemente, Morita (29), Harinasuta y Maegraith (14), MaeGRAITH (26) y MELENEY (27), comprobaron la existencia de una enzima proteolítica de origen amibiano, y el último de estos autores expresa que dicha enzima se comporta como un antígeno débil.

Con anterioridad, Meleney y Frye (28) habían ya demostrado que la reacción de fijación del complemento era negativa en los portadores sanos y que dicho fenómeno se debía a que las amebas, en esos casos, localizándose en la luz del intestino, no estimulaban la formación de anticuerpos séricos.

SHAFFER y ANSFIELD (31), trabajando con diversas cepas de cultivos de amebas, demostraron además, en los animales de experimentación, que algunas de ellas son muy antigénicas y otras no.

Finalmente, SWARTZWELDER y AVANT (32) demuestran experimentalmente en perros que en los casos de disentería aguda se desarrollan procesos inmunitarios defensivos pero que cuando las amebas se localizan tan sólo en el intestino estos procesos no se verifican.

En referencia a manifestaciones alérgicas por localización intestinal del parásito KLATSKIN (23) y COHEN y CRIEP (5) señalan urticaria y edema angioneurótico; CARri (4) refiere asma y otras manifestaciones alérgicas en un 17,50 por ciento de un total de 120 amébicos, curados todos del estado alérgico después de la desparasitación. Herraiz et al. (15), además de dermatosis, señaló características "reacciones segundas" (amebides). D’ANTONI (9), amén de haber observado numerosas manifestaciones alérgicas cutáneas, opina que el parasitismo intestinal por E. bistolytica torna a los individuos alérgicos hacia 3 ó 4 alimentos, condición ésta que desaparece después de la desparasitación. DE LA Vega y Hoyo (10) encuentran el 15 por ciento de urticaria en 200 enfermos y más del 50 por ciento de éstos se curaron del estado alérgico después de la desparasitación. JimÉNEZ-Quirós (18) en 2000 universitarios encontró 1088 parasitados por diversos protozoarios y entre los afectados de amibiasis el 60 por ciento presentaban escozor conjuntival.

Finalmente, CORTÉs (6) señala las posibles relaciones que existirían entre parásitos alojados en cualquier sitio del organismo humano y las reacciones de hipersensibilidad que se derivarían de tal asociación.

En este segundo trabajo damos a conocer un caso de alteraciones oculares diversas, de tipo alérgico, causadas por endoparásitos. Una nota previ̊ ha sido ya publicada. (20).

\section{ESTUDIO CLINICO}

E. R. de C., mujer de 30 años de edad, de oficios domésticos.

Al examen médico general encontramos (marzo de 1951), en piel y mucosas, blefaritis descamativa, dermatitis pitiriasiforme en párpados y surcos paranasales, der- 
matitis seca de bordes anales; faringe eritematosa e hipertrofia amigdaliana, lengua geográfica, buen estado de higiene dental; laringe y oídos normales, mucosa nasal edematosa y discreta hipertrofia de cornetes; tiroides normal, tórax bien conformado; a la aus. cultación tiraje bronquial. Normocárdica, hipotensa (100/60). Abdomen con línea alba Integra, hígado y bazo en sus límites, sensibilidad cólica difusa, cuerda cólica descendente-sigmoidea, defensa tiflítica y para-umbilicales sensibles. Cuello y cuerpo uterinos normales. En regiones axilares, inguino-crurales y pies, ninguna evidencia de infección fungosa ni microbiana. Reflejos pupilares, abdominales y patelares muy activos. Chwostek positivo. Transiluminación de sinus paranasales negativa.

Triada sintomatológica alérgica de Capuani (hipotensión arterial, hiperreflexia tendínea y dermografismo urticariano persistente) positiva.

En anamnesis familiar anotamos: diversas manifestaciones alérgicas (urticaria, eczema, rinitis y asma) y oculares (queratitis ulcerativa).

En anamnesis personal remota, parasitosis intestinal (ascariasis, tricocefaliasis, amibiasis), exantemas comunes y parotiditis en la infancia. Ninguna manifestación alérgica hasta hace cinco años, época en que presentó por primera vez urticaria, debida a mostaza.

En anamnesis reciente, hace un año y cuatro meses, después de un parto normal, nerviosismo y depresión general, pasadas dolorosas abdominales post-prandiales, atribuídos por la paciente a conflictos familiares y conyugales. En esa época se presentó edema gigante en párpados, quemosis conjuntival y dos días después queratitis ulcerativa izquierda. La sintomatología fue cediendo en el término de dos semanas, pero a partir de esa fecha, los síntomas repitieron con extrema frecuencia (hasta tres veces por mes), en ocasiones acompañados de fiebre elevada $\left(40^{\circ} \mathrm{C}\right.$ y más), presentándose edema gigante en párpados, labios y mentón, unas veces más acentuado a izquierda, otras a derecha o bilateralmente. Los síntomas oculares fueron también caprichosos en su localización y consistieron en quemosis, glaucoma agudo y queratitis ulcerativa, con lesiones variables en extensión y profundidad, no de naturaleza microbiana sino más bien alérgica, a juzgar por la subintrancia de los paroxismos y la rápida tendencia regresiva.

Del interrogatorio resultaron interesantes los siguientes datos: junto con los primeros síntomas cutáneos y oculares se presentó rinitis vasomotora, que la paciente relacionó con inhalantes comunes (polvo, perfumes, insecticidas), y una sintomatología espástica bronquial subintrante a las crisis más intensas de rinitis. Contemporáneamente observó que el chocolate, carne de cerdo, pescado y mostaza le producían urticaria. Las manifestaciones oculares, en cambio, se presentaban siguiendo ritmo propio pero precedidas de desórdenes intestinales (cólicos, cliarrea, tenesmo).

Los resultados de los exámenes de laboratorio fueron los siguientes: orina normal; leucocitosis ( 12.500 leucocitos por $\mathrm{mm}^{3}$ ) con eosinofilia del 17 por ciento; velocidad de eritrosedimentación $12 \mathrm{~mm}^{3}$ la primera hora; en exámenes de heces se encontraron numerosos huevecillos de Ascaris lumbricoides y trofozoitos y quistes de Entamoeba histolytica.

De las noventa intradermorreacciones que le practicamos, tan sólo las siguientes dieron respuesta positiva: mostaza $(+++)$, polvo casero $(++)$, espinaca $(++)$ e histamina $(++++)$. Las pruebas de parche con cosméticos, insecticidas, jabones, fueron negativas a las 48 horas.

En vista de la poca especificidad demostrada frente a sustancias corrientemente imputables de fenómenos de sensibilización, se procedió a desparasitar a la paciente con el afán de lograr establecer algún nexo, ex juvantibus, entre parasitosis intestinal y fenomenología alérgica.

Iniciamos el tratamiento de la ascaridiasis con hexilresorcinol, un gramo diario seguido de purgante salino de arrastre dos horas después. Expulsó a la segunda evacuación seis vermes adultos, pero presentó, casi de inmediato, edema palpebral, dolores en ambos ojos, quemosis izquierda muy acentuada y violenta jaqueca acompañada de vómito.

Atendida de urgencia le indicamos tratamiento sintomático con ACTH inyecta- 
do, un antihistamínico y Prostigmine per os, obteniéndose remisión de los síntomas oculares y cutáneos en término de dos semanas.

Iniciamos entonces el tratamiento antiamibiano con $0,50 \mathrm{gm}$ de W'intodón y 0,25 gm de Aralén, tres al día durante diez días consecutivos, acompañado de dieta con pocos residuos, un moderador de la peristalsis intestinal y un complejo polivitamínico.

Al siguiente día de haber inicidao esta terapia se presentaron de nuevo los síntomas edematosos y la tensión intraocular, pero el uso de ACTH inyectado y el antihistamínico per es permitió finalizar el tratamiento y asistir a la rápida regresión de todas las manifestaciones alérgicas.

Al finalizar el mes de junio, se presentó un nuevo paroxismo edematoso palpebral derecho, glaucoma agudo del mismo lado y fiebre elevada $\left(40,5^{\circ} \mathrm{C}\right)$. Examinada la paciente por uno de nosotros, la sintomatología fue nuevamente interpretada como alérgica y se le suministró de inmediato una ampolla de adrenalina en agua, 10 cc. de hiposulfito de calcio I.V. y dos cápsulas de Benadryl. La fiebre cedió por crisis, los síntomas desaparecieron en el término de dos horas y durante varios días las condiciones oftálmicas y cutáneas fueron muy satisfactorias. Un nuevo examen de heces reveló la presencia de huevecillos inmaduros de Ascaris lumbricoides. Repetimos el tratamiento con hexilresorcinol consiguiendo la expulsión de dos vermes de poco tamaño, pero contemporáneamente se presentaron disturbios oculares, dolorosos y congestivos, y fuerte jaqueca, que sin embargo fueron rápidamente controlados con dos ampollas de adrenalina acuosa mezclada con Gradualina (Life) a intervalo de doce horas una de la otra.

A partir de ese momento y durante un año y tres meses la paciente no presentó ningún otro tipo de manifestación alérgica.

Durante ese período se practicaron varios controles oftalmológicos que pusieron de manifiesto tan sólo cicatrices corneales, y todos los exámenes coproparasitológicos fueron negativos. Una intradermorreacción con alergeno de Ascaris sıum dio reacción inmediata positiva $(++t+)$ y se acompañó de quemosis fugaz.

En octubre de 1952 y después de algunas horas de sentir la paciente trastornos abdominales presentó un nuevo paroxismo ocular, rápidamente controlado con adrenalina-gradualina, hiposulfito de calcio I.V. y Benadryl per os. Al siguiente día el examen coproparasitoscópico demostró presencia de E. bistolytica (trofozoitos y quistes). De inmediato se inició tratamiento a base de Fugillin (Upjohn) y de adrenalina-gradualina, durante 10 días, no observándose ningún trastorno secundario.

Nueve meses después presentó recaída en ojo izquierdo (quemosis intensa y queratitis limbal) y edema angioneurótico en ambos párpados. Al examen de heces encontramos huevecillos de Ascaris lumbricoider. Siguiendo la terapeútica anteriormente probada eliminó cuatro parásitos jóvenes.

A partir de julio de 1953 en que los nexos entre ambas parasitosis y manifestaciones alérgicas fueron clínicamente patentes, a la paciente se le suministraron periódicamente tratamientos profilácticos con ascaricidas y amebicidas. Ninguno de éstos produjo el mínimo disturbio ocular, cutáneo o respiratorio, y desde esa fecha hasta el presente ninguna manifestación alérgica de las referidas ha repetido, así como tampoco ninguno de los numerosos exámenes de heces ha révelado la presencia de parásitos.

\section{DISCUSION}

Del presente caso clínico pueden hacerse varias consideraciones en relación a los posibles alergenos responsables. Después de lo dicho anteriormente no parecen quedar dudas sobre la capacidad alergizante de Ascaris lumbricoides. En cambio, en relación a E. bistolytica, el fenómeno no ha sido bien estudiado puesto que ningún autor ha demostrado claramente su papel en fenómenos de hipersensibilidad. Sin embargo, la capacidad antigénica de las amebas queda de- 
mostrada por la reacción de Craig y los trabajos de Meleney y Frye (28), MeLeney (27), Shaffer y Ansfield (31), y Swartzwelder y Avant (32). Además, por analogía con otros protozoarios (tisulares y no tisulares) se puede deducir que sustancias elaboradas por el parásito, a expensas del organismo o de la flora intestinal (normal o patológica), pueden fungir como alergenos, aunque débiles.

Por otro lado, las siguientes interrogantes pueden establecerse en casos de esta naturaleza para tratar de explicar los fenómenos: a) si el alergeno específico pudiera ser un hapteno que asociado a proteínas del organismo forme un antígeno completo; b) si dicho alergeno pudicre actuar en forma no específica, es decir, no con base en una reacción antígeno-anticuerpo, sino desencadenando el paroxismo por repercusión general sobre el organismo; c) que los fenómenos se suceden de acuerdo con la explicación de D'ANTONI (9) de que la presencia de amebas vuelve alérgico al individuo a determinados alimentos y ch) 'si de la acción lítica tisular resultaren sustancias antigénicas capaces de sensibilizar y producir sucesivamente reacciones antígeno-anticuerpo cada vez que exista actividad histolítica, o sea cuando hay infección intestinal o extraintestinal sintomática y que es cuando también tiene lugar la reacción de Craig.

Nuestra paciente reunía elementos clínicos para considerarla alérgica: antecedentes familiares, antecedentes personales remotos (urticaria por mostaza), antecedentes recientes y signos clínicos (triada de Capuani). En referencia a las parasitosis responsables, la paciente presentó triada de Girolami (trastornos gastro-intestinales, manifestaciones alérgicas y cosinofilia sanguínea) atribuible a la ascariasis; además, en relación con el mismo parásito, las manifestaciones alérgicas extraoculares encuentran apoyo en los trabajos ya citados de EARL (11) y LipPi y TRIPODI (25). En relación a amibiasis la paciente mostró sintomatología cólica característica, asma y edema angioneurótico, estos dos últimos explicables con base en los trabajos de Carri (4), Cohen y CRIEP (5) y KLATSKin (23), ya citados.

Sin embargo, los puntos más sugestivos de la relación alérgica de nuestro caso, aunque no tengan demostración inmunológica, están a cargo del decurso clínico así: a) la infección intestinal por Ascaris lumbricoides y Entamoeba histolytica mantuvo activa una sintomatología alérgica cutánea, respiratoria y ocular; b) la suministración de un ascaricida produjo fenómenos generales (cutáneos y oculares en particular) cuya explicación está más bien de acuerdo con la absorción del alergeno parasitario que con lo enunciado por CoRTÉs (6) (las drogas que se utilizan en la desparasitación actúen también como of ensores inmunológicos) ya que la repetición de la misma droga, sin ascariasis, no fungió como ofensor inmunológico; c) idéntico proceso fue observado con los amebicidas; $\mathrm{ch}$ ) se presentaron recidivas alérgicas durante las reinfecciones; d) la adrenalina inyectada resultó ser el mejor medicamento para prevenir la ulceración corneal y disminuir el glaucoma agudo ya presentado; y e) la curación clínica, de toda manifestación alérgica (cutánea, respiratoria y ocular) correspondió,•prolongándose ya por muchos años, a la ausencia de los agentes parasitarios causales. 


\section{CONCLUSIONES}

El estudio del presente caso nos hace llegar a las siguientes conclusiones:

1) En sujetos alérgicos, la investigación de factores etiológicos en rela. ción a manifestaciones oculares, no debe circunscribirse a los comúnmente men. cionados en la literatura clásica.

2) Cualquier parásito intestinal debe considerarse como alergeno en potencia (completo o incompleto), capaz de dar hipersensibilidad ocular, aunque, hasta el presente, la participación de los mismos haya sido muy poco estudiada.

3) No siempre, en estos casos, la comprobación inmunológica corrobora el diagnóstico; el criterio clínico, la observación detenida y recíproca colaboración entre alergólogo, oftalmólogo y parasitólogo, conduce a los mejores resultados.

4) La posibilidad de queratitis ulcerativa y glaucoma agudo, recidivantes, en relación a parasitismo intestinal (Ascaris y amebas) queda planteada.

5) En casos incipientes de queratitis y glaucoma agudo, de naturaleza alérgica, el uso de adrenalina acuosa parentérica, debe scr el medicamento de clección.

\section{RESUMEN}

Se presenta un caso de queratitis ulcerativa y glaucoma agudo recidivante, cuyo decurso clínico pudo seguirse durante más de nueve años. El edema angioneurótico facial, la rinitis y el asma hicieron sospechar la naturaleza alérgica del proceso que quedó demostrada y definitivamente ligada al parasitismo por Ascaris lumbricoides y Entamoeba bistolytica.

El uso de adrenalina acuosa, como preventivo o abortivo de las reacciones oculares, demostró ser la más eficaz entre las drogas empleadas.

Los autores insisten en que la capacidad alergénica de los parásitos intestinales, debe tenerse muy en cuenta en casos clínicos como el presente.

\section{SUMMARY}

A case of ulcerative keratitis and relapsing acute glaucoma is reported, whose clinical course was followed for over 9 years. The recurrent paroxysmal character of the case, with the coincidence of ocular manifestations with facial angioneurotic edema, rhinitis and asthma, led to the investigation of a possible allergic etiology. No common allergen was found to be involved; but the concomitance of intestinal symptoms with presence of Ascaris lumbricoides eggs and Entamoeba bistolytica cysts and trophozoites in the feces suggested investigation of the nexus between the above parasitoses and the ocular and extraocular manifestations.

During treatments there were, consistently, allergic manifestations; but inclusion of intramuscular aqueous addrenaline among the drugs used proved 
effective as a preventive or abortive factor of the ocular reactions.

After the antiparasitic treatments the symptoms disappeared completely; however, reinfection of either of the two parasites caused new allergic manifestations. The permanent cure of ocular (keratitis and glaucoma) and extraocular (angioneurotic edema, rhinitis, asthma) manifestations corresponded to permanent elimination of the parasites.

Having revised the literature available on the subject, the authors believe the present case to be the first report on ulceral keratitis and allergic glaucoma in relation to Ascaris lumbricoides and Entamoeba bistolytica. They recommend, moreover, that the allergenic nature of intestinal parasites not well studied immunologically should be suspected in cases such as the present one.

\section{BIBLIOGRAFIA}

1. Alimuddin, M.

1955. Vernal conjunctivitis. Brit. J. Ophth., 39: 160.

2. Campbell, D. H.

1937. The immunological specificity of a polysaccharid fraction from some common parasitic helminths. J. Parasitol., 23: 348-353.

3. Capunini, G. F.

1945. Allergia e Malattie Allergiche. Ed. Minerva Mcdica, S. A., Torino. xii + $830 \mathrm{pp}$.

4. CARRI, L.

1948. Amibiasis intestinal y alcrgias respiratorias. Prensa Médica A'gentina, 35: 1477.

5. Cohen, S. G., \& L. Criep

1950. Urticaria and angioedema in association with amebiasis. Am. Practitioners, 1: 246.

6. CORTÉs, J. L.

1958. Alergia Clinica. Principales características en México. Impresiones Modernas, S. A., México. 2 Tomos, xxiv + 1040 pp.

7. Craig, C. F.

1927. Observations on the hemolytic, cytolytic and complement-binding properties of extracts of Entamoeba bistolytica. Amer. J. Trop. Med., 7: 225-240.

8. Craig, C. F.

1929. The technique and results of a complement fixation test for the diagnosis of infections with Entamoebs bistolytica. Amer. J. Trop. Med., 9: 277-296.

9. D'Antoni, J. S.

1951. Comunicación personal.

10. De la Vega, J. M., \& C. M. Hoyo

1949. Amibiasis y urticaria. Rev. Mex. de Alergologia, Monterrey, México, 1(1): 22. 
11. EARL, K. V.

1944. Asthma produced by Ascaris infestation. Tr. Roy. Soc. Trop. Mcd. Hyg., 37: 451 .

12. Fuelleborn, F., \& W. Kikuth

1929. Über dic Allergie des Menschen gegenüber Ascaris. Klin. Wscbr.,: 1988.

13. Hansen, H., \& W. Berger

1929. Practitioner, 123: 52.

14. Harinasuta, C., \& B. G. Maegraith

1954. Proteolytic enzyme activity of Eiltamoeba bistolytica. Demonstration. Trans. Rov. Soc. Trop. Med. \& Hyg.. 48: 285.

15. Herraiz, L., A. M. Mom \& F. M. Noussitou

1948. Alergia Dermatológica. Librería y Editorial "El Ateneo", Buenos Aires, 344 pp.

16. JADASSOHN, W.

1928. Allergiestudien bei der Ascaridenidiosynkrasie. Arch. f. Derml. "Syph., 156: 690 .

17. JimÉnEZ-Quirós, O.

1959. Ascariasis con manifestaciones nerviosas y eosinofilia del liquor. Rel. Biol. Trop., 7 (1): 67-74.

18. JIMÉNEZ-QUiRÓS, O.

1958. Parasitosis intestinal en el universitario costarricense. II. Protozoosis. Rev'. Biol. Trop., 6 (2): 191-199.

19. Jiménez-Quirós, O., R. R. Brenes \& P. L. Vieto

1958. Parasitosis intestinal en el universitario costarricense. I. Helmintiasis. Ret. Biol. T'rop. 6 (1): 113-122.

20. Jiménez-Quirós, O., P. L. Vieto, R. Saborío \& A. Agüero

1959. Nota previa. Manifestaciones alérgicas en Oftalmología. Rev. Biol. Tropl., 7 (1): 131-132.

21. Imménez-Quirós, O., P. L. Viæto, R. SAborío, \& A. Agürro

1960. Manifestaciones alérgicas en Oftalmología. I. Retinitis alérgica a infección focal estafilocóccica: su importancia diagnóstica y tratamiento exclusivo con autoalérgenos, . Rev. Biol. Trop., \& (2): 271-278.

22. Kag $\Lambda$, I. G. \& Cols.

1958. Serum-agar double diffusion studies with Ascaris antigens. II. Assay of whole worm and tissue antigen complexes. J. Immunol. 80: 400-406.

23. KLatskin, G.

1946. Amebiasis in American troops in India. Ann. Int. Med., 25: 772.

24. Kourí, P.

1949. Lecciones de parasitologia y medicina tropical. Tomo II. Helmintología humana. 3" Ed. Talleres Tipográficos de "El Siglo XX", Brasil 153, La Habana, Cuba, Ixxxii +856 pp. 
25. LipPI, M. \& P. Trupodi

1955. Allergia nell'Ascaridosi. Aich. Ital. Sci. Med. Trop. e Parassitol., 36: 65-104.

26. Maegraith, B. G.

1955. The pathogenicity of plasmodia and entamoebae. In Mechanisms of Microbial Patbogenicity. Cambridge University Press, London,: 206-229.

27. Meleney, H. E.

1957. Some unsolved problems in amebiasis. Amer. J. Trop. Med. Hyg., 6 (3): 487-498.

28. Meleney, H. E., \& W. W. Frye

1937. Practical value and significance of the complement fixation reaction in amebiasis. Amer. J. Public Health, 27: 505-510.

29. MORITA, Y.

1938. Investigations on amoebic dysentery. XII. Toxicological studies of the extracts made from cultured dysenteric amoebae, J. Oriental Med., 28: 37 (citado en MAegraith).

30. Oliver-González, J.

1953. Adsorption of a isoagglutinogen-like substances of infections agents on human erythrocytes. Proc. Soc. Exptl. Biol. Med., 84 (3): 520.522.

31. Shaffer, J. G. \& J. Ansfield

1956. The effect of rabbit antisera on the ability of Entamoeba bistolytica to phagocytose red blood cells, Amer. J. Trop. Med. Hyg., 5: 53-61.

32. Swartzwelder, J. C., \& W. H. Avant

1952. Immunity to amebic infection in dogs, Amer. J. Trop. Med. Hyg., 1: 567-575.

33. VANNI, V.

1952. Manual Práctico de Parasitología Médica. Ed. Bibliográfica Argentina. Cangallo 860, Buenos Aires, 398 pp.

34. ZoHN, B.

1931. Placental transmission of hypersensitiveness to Ascuris lumbricoides actively induced in the pregnant woman, Amer. J. Dis. Child., 57: 1067-1071. 